Cahiers $d u$ MONDE RUSSE

\section{Cahiers du monde russe}

Russie - Empire russe - Union soviétique et États indépendants

$43 / 4 \mid 2002$

Intellectuels et intelligentsia

\title{
James R. Harris, The great Urals
}

\section{Nathalie Moine}

\section{OpenEdition \\ Journals}

Édition électronique

URL : https://journals.openedition.org/monderusse/4049

DOI : $10.4000 /$ monderusse. 4049

ISSN : $1777-5388$

Éditeur

Éditions de l'EHESS

Édition imprimée

Date de publication : 30 décembre 2002

Pagination : 776-778

ISBN : 2-7132-1796-2

ISSN : $1252-6576$

\section{Référence électronique}

Nathalie Moine, "James R. Harris, The great Urals », Cahiers du monde russe [En ligne], 43/4 | 2002, mis en ligne le 03 juillet 2009, consulté le 03 septembre 2022. URL : http://journals.openedition.org/ monderusse/4049; DOI : https://doi.org/10.4000/monderusse.4049

Ce document a été généré automatiquement le 3 septembre 2022.

Tous droits réservés 


\title{
James R. Harris, The great Urals
}

\author{
Nathalie Moine
}

\section{RÉFÉRENCE}

James R. HARRIS, The great Urals. Regionalism and the evolution of the Soviet system. Ithaca-Londres, Cornell University Press, 1999, $230 \mathrm{p}$.

1 L'étude que James Harris a consacrée à la région de l'Oural apporte une contribution de poids à l'histoire du stalinisme des années 1930. Elle présente en effet l'originalité de décrire les phénomènes saillants de cette "seconde révolution" d'un point de vue décentralisé. Pour autant, l'auteur justifie moins son angle d'approche par la volonté de faire une histoire "vue d'en bas », au quotidien, ou de la périphérie, que par l'hypothèse selon laquelle les leaders régionaux furent des acteurs décisifs des prises de décision au sommet. Alors que l'historiographie s'était essentiellement intéressée aux débats et conflits qui firent rage à la fin des années 1920 au "Centre» et dont Stalin ressortit vainqueur, James Harris rappelle d'emblée le poids des responsables régionaux au sein du Comité central, ainsi que le caractère crucial du premier plan quinquennal dans le déploiement des ressources et le développement régional. Or, les dirigeants régionaux saisirent tout de suite les enjeux de la planification et la nécessité de défendre leurs intérêts, en compétition avec d'autres régions. L'ouvrage s'attache donc à démontrer combien la façon dont les dirigeants régionaux définirent les intérêts de la région qu'ils avaient en charge et leur capacité de pression façonnèrent à la fois les objectifs et le déroulement concret des mesures édictées par le pouvoir central.

Dans cette perspective, le choix de la région de l'Oural semble particulièrement pertinent : James Harris montre en effet combien la région possède déjà tout un passé de développement économique, dû pour l'essentiel à l'État, qui débute avec le lancement par Pierre le Grand d'une industrie métallurgique afin de préparer sa campagne contre les Suédois. Cependant, l'Oural a perdu sa prédominance dès la deuxième moitié du XIX ${ }^{e}$ siècle, à la fois sévèrement concurrencée par l'Ukraine et dépassée par les avancées technologiques. La révolution et, plus encore, le projet d'industrialisation massive au 
tournant des années 1920-1930 constituent des occasions essentielles pour l'Oural de retrouver son leadership, tout en la mettant en forte concurrence avec d'autres régions de l'espace soviétique : l'Ukraine toujours, mais aussi la Sibérie, le Kazakhstan ou encore l'Extrême-Orient.

3 Cette volonté de mainmise sur les ressources allouées par l'État explique les pressions exercées afin que l'Oural obtienne des taux de croissance de l'investissement industriel très ambitieux. Ce faisant, les dirigeants régionaux se mettent également dans une situation de forte demande de la part du pouvoir central en matière de production. Le plan grandiose de développement de l'Oural se heurte donc à un certain nombre d'obstacles: tout d'abord la nécessité de décupler la production de bois, source essentielle d'énergie de la région pour la métallurgie. Or, les nouveaux gisements forestiers à mettre en valeur se trouvent au nord de l'Oural, dans une région fort peu hospitalière, parfaitement dénuée d'infrastructures routières, sans parler du logement et du ravitaillement. En outre, l'Oural souffre d'un déficit de main-d'œuvre, conséquence en partie des craintes suscitées par le développement du chômage urbain au cours des années 1920. C'est donc cette question de main-d'œuvre qui éclaire un aspect essentiel de la thèse de Harris, à savoir les pressions forcenées des dirigeants de l'Oural sur le pouvoir central en matière de collectivisation et de dékoulakisation. D'une part, il s'agissait d'obtenir une collectivisation totale beaucoup plus étendue géographiquement que ce qui avait été prévu par le Centre à l'origine, afin de libérer de la force de travail dans les régions minières. D'autre part, il apparut clairement que l'exploitation des ressources forestières ne pouvait se faire qu'en ayant recours au travail forcé, ce qui explique les pressions locales pour augmenter les contingents de paysans dékoulakisés, déportés au nord de la région dans des conditions terribles que dénonça le Centre alors que les taux de mortalité montaient en flèche.

Le second apport essentiel du travail de Harris concerne les mécanismes de la Terreur: alors que les dirigeants régionaux doivent se couvrir face à l'échec du plan, de véritables cliques se développent, que le Centre s'emploie à casser à la fin des années 1930. En réalité, cette explication doit être replacée dans une interprétation plus générale de la saignée des années 1937-1938, en montrant que les mesures répressives dont sont victimes les élites régionales ne constituent sans doute qu'un des fils d'explication des années de terreur.

Dans sa conclusion, l'auteur note que, paradoxalement, les pouvoirs régionaux sortent renforcés à la fin des années 1930, un des traits saillants du système soviétique, qui le conduit à sa perte et bloque encore les réformes.

6 Le travail de Harris repose sur des archives importantes, dans un cadre théorique encore très marqué par les débats révisionnistes. Il s'agit de montrer que les dirigeants régionaux sont des acteurs de la prise de décision, et non pas le seul Centre et encore moins Stalin lui-même. En revanche, les aspects culturels n'entrent jamais en ligne de compte. Ainsi, on chercherait en vain ce qui définit spécifiquement l'identité régionale à l'époque des années 1930. L'analyse proposée du comportement des dirigeants régionaux est en effet tout à fait semblable à celle qu'on pourrait faire des motivations d'un directeur d'entreprise ou d'administration, ce qui mériterait au moins une discussion.

7 Néanmoins, l'ouvrage, s'appuyant tant sur des archives centrales que régionales, propose une lecture cohérente des aspects fondamentaux du stalinisme, notamment sur les origines du développement du Goulag. 